\title{
Peter Brooks, Balzac alla fine della vita di Freud
}

\section{Marco Stupazzoni}

\section{(2) OpenEdition}

\section{Journals}

\section{Edizione digitale}

URL: https://journals.openedition.org/studifrancesi/3145

DOI: $10.4000 /$ studifrancesi.3145

ISSN: 2421-5856

\section{Editore}

Rosenberg \& Sellier

\section{Edizione cartacea}

Data di pubblicazione: 1 juillet 2013

Paginazione: 471

ISSN: 0039-2944

\section{Notizia bibliografica digitale}

Marco Stupazzoni, «Peter Brooks, Balzac alla fine della vita di Freud», Studi Francesi [Online], 170 (LVII |

II) | 2013, online dal 30 novembre 2015, consultato il 02 février 2023. URL: http://

journals.openedition.org/studifrancesi/3145; DOI: https://doi.org/10.4000/studifrancesi.3145

\section{Questo documento è stato generato automaticamente il 2 février 2023.}

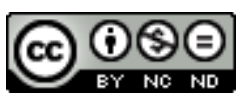

Creative Commons - Attribuzione - Non commerciale - Non opere derivate 4.0 Internazionale - CC BYNC-ND 4.0

https://creativecommons.org/licenses/by-nc-nd/4.0/ 


\title{
Peter Brooks, Balzac alla fine della vita di Freud
}

\author{
Marco Stupazzoni
}

\section{NOTIZIA}

PETER BROOKS, Balzac alla fine della vita di Freud, «L'Indice dei libri del mese», anno XXIX, $\mathrm{n}^{\circ} 9$, settembre 2012, pp. 14.

1 È riportata, in questa pagina, la parte iniziale dell'intervento pronunciato da P. Brooks in occasione del colloquio «C'è del metodo in questa follia. L'irrazionale nella cultura romantica», organizzato dalla Fondazione Malatesta a Santarcangelo di Romagna il 25-26 maggio 2012.

2 Il giorno prima di chiedere l'iniezione fatale, Freud termina la lettura di un romanzo di Balzac, La Peau de chagrin, un'opera che, come affermò lo stesso Freud, «riguarda la restrizione e l'inedia» e che rivela, per il protagonista Raphaël de Valentin, l'esito fatale del desiderio e della sua soddisfazione. La scoperta della realizzazione del desiderio in tutta la sua pienezza, scrive Brooks, «è anche scoperta della morte come inevitabile conseguenza del desiderio». La pulsione di morte al servizio del principio del piacere riporta l'individuo indietro, verso ciò che Freud chiama, in Al di là del principio di piacere (1920), la «quiete primordiale». Le modalità a tinte gotico-melodrammatiche su cui poggiano la struttura e i ritmi narrativi del romanzo mettono in rilievo anche gli «aspetti gotici e melodrammatici della psicoanalisi stessa»: in questo senso, la psicoanalisi propone una «melodrammatizzazione della vita psichica, esattamente come Balzac propone un intenso psicodramma. Balzac e Freud [...] stanno tra di loro in un rapporto irrealizzato, mettendo ognuno in evidenza un aspetto essenziale dell'altro». 